\title{
PENGARUH PERTUMBUHAN DAN PRODUKSI BAWANG MERAH (ALLIUM ASCALONICUM.L) TERHADAP PEMBERIAN KOMPOS LIMBAH RUMPUT LAUT (GRACILARIA SP.)
}

\author{
Effect Red Growth and Production (Allium Ascalonicum.L) On The Granting Of Sea \\ Grass Composition (Gracilaria Sp.) \\ Zaira Yuliantika ${ }^{1}$, Achmad Nizar $^{2}$ \\ 1Jurusan Penyuluhan Pertanian Berkelanjutan - Politeknik Pembangunan Pertanian Malang \\ Jl. Dr. Cipto 144A Lawang - Malang 65211 \\ email : factoipso5@gmail.com
}

\begin{abstract}
ABSTRAK
Penelitian dilaksanakan pada bulan Januari sampai Maret 2019 di Lahan Praktikum Desa Kabuaran Kecamatan Grujugan Kabupaten Bondowoso. Metode penelitian menggunakan rancangan acak kelompok faktorial (RAKF). Setiap perlakuan diulang 3 kali ulangan, maka terdapat 36 petak percobaan. Variabel pengamatan meliputi komponen pertumbuhan dan komponen hasil. Jika hasil perhitungan sidik ragam menunjukan hasil yang berbeda nyata maka dilanjutkan dengan Uji Duncan pada taraf 5\%. Hasil penelitian menunjukan Penggunaan Kompos Limbah Rumput Laut dosis $3 \mathrm{~kg}$ dengan penambahan POC Nasa/20cc mempengaruhi secara nyata jumlah daun, jumlah umbi, berat umbi basah, dan berat umbi kering.
\end{abstract}

Kata kunci: Kata Kunci : Bawang Merah; Kompos Rumput Laut; Organik Pertumbuhan; Peningkatan Hasil Panen; Produksi

\begin{abstract}
The purposes of research were to know the concentration of bio growth regulator made of bamboo shoot on increasing the production of shallots. This research was conducted in the field of Vocational College of Agricultural Extension of Malang from January to March 2018. Randomized block design was used with 6 replications. The treatments were: $P 0=$ without treatment, $P 1=10 \mathrm{ml} / \mathrm{Lt}, P 2=40 \mathrm{ml} / \mathrm{Lt}$, $P 3=70 \mathrm{ml} / \mathrm{Lt}$. the seed was soaked in water 15 minute. The results showed the concentration of $40 \mathrm{ml} /$ Lt of water significantly influenced on Leaf number, bulb number, wet weight of bulb, and dray weight of bulb.
\end{abstract}

Keywords : Keywords: Increased Harvest Results; Organic Growth; Production; Red onion; Seaweed Compost 


\section{PENDAHULUAN}

Salah satu komuditas sayuran yang mempunyai arti penting bagi masyarakat baik dari segi ekonomisnya maupun kandungan gizinya yang tinggi adalah Bawang merah (Allium ascalonicum L.). Peningkatan produksi juga perlu dilakukan dengan melakukan pengaplikasian rumput laut sebagai pupuk organik (Yunizal, 2014). Selanjutnya Menurut Rezagama (2015) Proses pengomposan dengan menggunakan keranjang Takakura merupakan proses pengomposan aerob, dimana udara merupakan faktor utama yang dibutuhkan sebagai asupan penting dalam proses pertumbuhan mikroorganisme yang menguraikan sampah menjadi kompos.

Desa Kabuaran Kecamatan Grujugan Kabupaten Bondowoso diproyeksikan sebagai kawasan agribisnis hortikultura bawang merah. Pada tahun 2017 pemerintah daerah kabupaten Bondowoso mendapatkan bantuan dari pemerintah pusat untuk pengembangan agribisnis hortikultura yang akan dialokasikan pada komoditi bawang merah dengan potensi produksi bawang merah di Desa Kabuaran yang memiliki ketinggian sekitar 400 sampai 700 meter diatas permukaan laut, mencapai 15,6 ton hingga 18 ton perhektar.
Penelitian telah dilaksanakan di lahan praktikum Desa Kabuaran Kecamatan Grujugan Kabupaten Bondowoso pada Bulan Januari sampai Maret 2019. Rancangan penelitian menggunakan rancangan acak kelompok Faktorial (RAKF). Terdiri dari 12 perlakuan dan setiap perlakuan diulang 3 kali ulangan, maka terdapat 36 petak percobaan. Selanjutnya parameter yang diamati adalah tinggi tanaman, jumlah daun, jumlah umbi, berat umbi basah dan berat umbi kering. Data hasil pengamatan dianalisa menggunakan Annova Two Way, apabila ada perbedaan diuji dengan uji beda nyata menggunakan Duncan pada taraf 5\%.

\section{HASIL DAN PEMBAHASAN}

\section{Tinggi Tanaman}

Pada pengamatan tinggi tanaman bawang merah menggunakan alat ukur berupa mistar/jangka sorong dengan pengukuran diawali dari pangkal batang akar tanaman bawang merah hingga bagian ujung daun tanaman yang tertinggi terhadap setiap tanaman bawang merah. Seiring dengan bertambahnya umur maka tanaman bawang merah pun akan semakin tinggi. Pengamatan pertumbuhan bawang merah dilakukan sebanyak 5 kali pada tinggi tanaman bawang merah. Adapun penyajian data tinggi tanaman disajikan sebagai berikut: 
Tabel 1. Rekapitulasi Pengamatan Tinggi Tanaman

\begin{tabular}{cccccc}
\hline \multirow{2}{*}{ Perlakuan } & \multicolumn{6}{c}{ Hasil Rata-rata Pengamatan Tinggi Tanaman Bawang merah } \\
& 10 HST & 20 HST & 30 HST & 40 HST & 50 HST \\
\hline $\mathrm{P}_{0} \mathrm{D}_{1}$ & $16,73 \mathbf{a}$ & $17,26 \mathbf{a}$ & $17,85 \mathbf{a}$ & $18,93 \mathbf{a}$ & $20,36 \mathbf{a}$ \\
$\mathrm{P}_{0} \mathrm{D}_{2}$ & $15,70 \mathbf{a}$ & $16,16 \mathbf{a}$ & $17,04 \mathbf{a}$ & $17,85 \mathbf{a}$ & $20,53 \mathbf{a}$ \\
$\mathrm{P}_{0} \mathrm{D}_{3}$ & $16,20 \mathbf{a}$ & $16,66 \mathbf{a}$ & $17,42 \mathbf{a}$ & $18,81 \mathbf{a}$ & $20,26 \mathbf{a}$ \\
$\mathrm{P}_{1} \mathrm{D}_{1}$ & $20,43 \mathbf{a}$ & $21,10 \mathbf{a}$ & $21,86 \mathbf{a}$ & $22,70 \mathbf{a}$ & $23,33 \mathbf{a}$ \\
$\mathrm{P}_{1} \mathrm{D}_{2}$ & $21,80 \mathbf{a}$ & $22,23 \mathbf{a}$ & $22,83 \mathbf{a}$ & $23,26 \mathbf{a}$ & $24,13 \mathbf{a}$ \\
$\mathrm{P}_{1} \mathrm{D}_{3}$ & $22,44 \mathbf{a}$ & $23,06 \mathbf{a}$ & $23,54 \mathbf{a}$ & $24,00 \mathbf{a}$ & $25,00 \mathbf{b}$ \\
$\mathrm{P}_{2} \mathrm{D}_{1}$ & $27,76 \mathbf{a}$ & $28,36 \mathbf{a}$ & $29,20 \mathbf{a}$ & $29,96 \mathbf{a}$ & $30,93 \mathbf{a}$ \\
$\mathrm{P}_{2} \mathrm{D}_{2}$ & $21,50 \mathbf{b}$ & $28,50 \mathbf{b}$ & $28,90 \mathbf{b}$ & $30,10 \mathbf{b}$ & $31,00 \mathbf{b}$ \\
$\mathrm{P}_{2} \mathrm{D}_{3}$ & $21,00 \mathbf{b}$ & $29,13 \mathbf{b}$ & $29,70 \mathbf{b}$ & $30,56 \mathbf{b}$ & $31,40 \mathbf{b}$ \\
$\mathrm{P}_{3} \mathrm{D}_{1}$ & $27,23 \mathbf{a}$ & $27,90 \mathbf{a}$ & $28,35 \mathbf{a}$ & $28,86 \mathbf{a}$ & $30,16 \mathbf{b}$ \\
$\mathrm{P}_{3} \mathrm{D}_{2}$ & $27,30 \mathbf{a}$ & $28,13 \mathbf{a}$ & $28,55 \mathbf{a}$ & $29,46 \mathbf{a}$ & $30,33 \mathbf{a}$ \\
$\mathrm{P}_{3} \mathrm{D}_{3}$ & $27,16 \mathbf{a}$ & $27,93 \mathbf{a}$ & $28,41 \mathbf{a}$ & $29,16 \mathbf{a}$ & $29,86 \mathbf{a}$ \\
\hline
\end{tabular}

*Angka yang diikuti huruf yang tidak sama pada kolom yang sama menunjukkan perbedaan yang nyata.

Pada tabel 1. Menunjukkan rekapitulasi tinggi tanaman bawang merah pada pengamatan 10 HST sampai 50 HST. Hasil rata-rata pengamatan tinggi tanaman bawang merah menunjukkan adanya perbedaan signifikan pada 10 HST sampai 40 HST.

Kompos limbah rumput laut berpengaruh terhadap pertumbuhan bawang merah terutama pada tinggi tanaman. Kompos limbah rumput laut mampu memacu pertumbuhan bawang merah sehingga pertumbuhan tanaman bawang merah baik. Adanya perbedaan nyata pada 10 HST sampai 40 HST dikarenakan Kompos limbah rumput laut mempengaruhi pertumbuhan sedangkan pada 50 HST tidak menunjukkan adanya perbedaan signifikan dikarenakan pertumbuhan umbi bawang merah pada data jumlah daun tanaman bawang merah pada tiap perlakuan disajikan sebagai berikut.

Tabel 2. Rekapitulasi Pengamatan Jumlah Daun

\begin{tabular}{cccccc}
\hline Perlakuan & \multicolumn{5}{c}{ Hasil Rata-rata Pengamatan Jumlah Daun Bawang merah } \\
& 10 HST & 20 HST & 30 HST & 40 HST & 50 HST \\
\hline $\mathrm{P}_{0} \mathrm{D}_{1}$ & $7,76 \mathbf{a}$ & $16,93 \mathbf{~ b}$ & $18,5 \mathbf{~ b}$ & $21,89 \mathbf{~ b}$ & $24,3 \mathbf{~ b}$
\end{tabular}

tinggi tanaman, tidak optimal menjelang 50 HST.

Menurut Basmal dkk (2009) kompos mengandung zat pengatur tumbuh seperti sitokinin (kinetin dan zeatin), auksin/IAA, giberelin (GA3). Namun untuk mempercepat dan meningkatkan kualitas kompos, timbunan bahan yang akan dijadikan kompos perlu diberi tambahan pupuk yang mengandung hara sehingga jumlah hara yang terkandung akan semakin tinggi (Rosmarkam dan Yuwono, 2002).

\section{Jumlah Daun}

Pengamatan jumlah daun tanaman bawang merah dilakukan dengan cara menghitung jumlah daun satu persatu pada setiap perlakuan Adapun penyajian 


\begin{tabular}{cccccc}
$\mathrm{P}_{0} \mathrm{D}_{2}$ & $7,00 \mathbf{a}$ & $17,3 \mathbf{b}$ & $19,4 \mathbf{b}$ & $21,94 \mathbf{b}$ & $24,13 \mathbf{b}$ \\
$\mathrm{P}_{0} \mathrm{D}_{3}$ & $6,80 \mathbf{a}$ & $16,2 \mathbf{b}$ & $18,4 \mathbf{b}$ & $24,14 \mathbf{b}$ & $27,9 \mathbf{c}$ \\
$\mathrm{P}_{1} \mathrm{D}_{1}$ & $8,23 \mathbf{a}$ & $18,2 \mathbf{b}$ & $19,4 \mathbf{b}$ & $21,72 \mathbf{b}$ & $24,43 \mathbf{c}$ \\
$\mathrm{P}_{1} \mathrm{D}_{2}$ & $8,70 \mathbf{a}$ & $19,26 \mathbf{b}$ & $20,86 \mathbf{b}$ & $23,94 \mathbf{b}$ & $27,8 \mathbf{c}$ \\
$\mathrm{P}_{1} \mathrm{D}_{3}$ & $8,56 \mathbf{a}$ & $18,4 \mathbf{b}$ & $19,26 \mathbf{b}$ & $24,33 \mathbf{b}$ & $27,83 \mathbf{c}$ \\
$\mathrm{P}_{2} \mathrm{D}_{1}$ & $10,73 \mathbf{b}$ & $21,90 \mathbf{b}$ & $23,23 \mathbf{b}$ & $32,35 \mathbf{c}$ & $40,1 \mathbf{c}$ \\
$\mathrm{P}_{2} \mathrm{D}_{2}$ & $11,43 \mathbf{b}$ & $21,60 \mathbf{b}$ & $22,93 \mathbf{a}$ & $32,31 \mathbf{c}$ & $40,2 \mathbf{c}$ \\
$\mathrm{P}_{2} \mathrm{D}_{3}$ & $11,56 \mathbf{c}$ & $21,63 \mathbf{b}$ & $23,23 \mathbf{b}$ & $32,78 \mathbf{c}$ & $40,7 \mathbf{c}$ \\
$\mathrm{P}_{3} \mathrm{D}_{1}$ & $9,70 \mathbf{a}$ & $19,26 \mathbf{a}$ & $21,63 \mathbf{a}$ & $32,28 \mathbf{b}$ & $39,9 \mathbf{c}$ \\
$\mathrm{P}_{3} \mathrm{D}_{2}$ & $9,76 \mathbf{a}$ & $20,73 \mathbf{a}$ & $21,66 \mathbf{b}$ & $32,38 \mathbf{c}$ & $39,3 \mathbf{c}$ \\
$\mathrm{P}_{3} \mathrm{D}_{3}$ & $8,53 \mathbf{a}$ & $19,26 \mathbf{a}$ & $21,6 \mathbf{a}$ & $33,57 \mathbf{b}$ & $39,3 \mathbf{c}$ \\
\hline *Angka yang diikuti huruf yang tidak sama pada kolom yang sama menunjukkan
\end{tabular}
perbedaan yang nyata.

Pada tabel 2. Menunjukkan rekapitulasi jumlah daun tanaman bawang merah pada pengamatan $10 \mathrm{HST}$ sampai $50 \mathrm{HST}$. Hasil rata-rata pengamatan jumlah daun tanaman bawang merah menunjukkan adanya perubahan signifikan pada 10 HST sampai 50 HST.

Peningkatan notasi pada $10 \mathrm{HST}, 20 \mathrm{HST}$, $30 \mathrm{HST}, 40 \mathrm{HST}, 50 \mathrm{HST}$ terjadi pada $\mathrm{P}_{2} \mathrm{D}_{3}$. Sehingga dapat dikatakan penggunaan Kompos Limbah Rumput Laut dosis $3 \mathrm{~kg}$ dengan penambahan POC Nasa/20cc mempengaruhi jumlah daun bawang merah.

Menurut Tjitrosopoemo (2005), Daun merupakan organ vegetatif pada tanaman yang penting untuk berlangsungnya proses fotosintesis. Selain itu, daun juga berperan penting dalam pengambilan zat-zat makanan, pengolahan zat-zat makanan, penguapan air, dan pernafasan. Unsur hara yang ditambahkan melalui pemupukan akan mengalami proses miniralisasi dan pelepasan ikatan kimia dari senyawa kompleks menjadi kation-kation yang dapat diserap tanaman (Jumin, 2008).

\section{Jumlah Umbi}

Pengamatan jumlah umbi bawang merah dilakukan dengan cara menghitung jumlah umbi bawang merah satu persatu pada setiap rumpunnya. Adapun penyajian data jumlah umbi bawang merah sebagai berikut.

Tabel 3. Rekapitulasi Pengamatan Jumlah Umbi

\begin{tabular}{cc}
\hline Perlakuan & $\begin{array}{c}\text { Rata-rata Pengamatan } \\
\text { Jumlah Umbi }\end{array}$ \\
\hline $\mathrm{P}_{0} \mathrm{D}_{1}$ & $6,9 \mathbf{a}$ \\
$\mathrm{P}_{0} \mathrm{D}_{2}$ & $6,0 \mathbf{a}$ \\
$\mathrm{P}_{0} \mathrm{D}_{3}$ & $7,1 \mathbf{a}$ \\
$\mathrm{P}_{1} \mathrm{D}_{1}$ & $7,80 \mathbf{a}$ \\
$\mathrm{P}_{1} \mathrm{D}_{2}$ & $10,2 \mathbf{a}$ \\
$\mathrm{P}_{1} \mathrm{D}_{3}$ & $12,49 \mathbf{a}$ \\
$\mathrm{P}_{2} \mathrm{D}_{1}$ & $12,80 \mathbf{a}$ \\
$\mathrm{P}_{2} \mathrm{D}_{2}$ & $15,10 \mathbf{c}$ \\
$\mathrm{P}_{2} \mathrm{D}_{3}$ & $15,51 \mathbf{c}$ \\
$\mathrm{P}_{3} \mathrm{D}_{1}$ & $14,90 \mathbf{b}$ \\
$\mathrm{P}_{3} \mathrm{D}_{2}$ & $14,55 \mathbf{b}$ \\
$\mathrm{P}_{3} \mathrm{D}_{3}$ & $14,35 \mathbf{b}$ \\
\hline
\end{tabular}

*Angka yang diikuti huruf yang tidak sama pada kolom yang sama menunjukkan perbedaan yang nyata. 
Tabel 3. menunjukkan adanya perbedaan nyata jumlah umbi tanaman bawang merah yang telah diamati. Peningkatan jumlah umbi bawang merah tertinggi terjadi pada perlakuan $\mathrm{P}_{2} \mathrm{D}_{3}$ dengan konsentrasi Kompos Limbah Rumput Laut dosis $3 \mathrm{~kg}$ disertai penambahan POC Nasa/20cc mempengaruhi jumlah umbi bawang merah. Hal ini disebabkan kandungan $\mathrm{N}$ pada kompos tersebut berperan aktif dalam pertumbuhan tanaman sehingga anakan bisa berkembang menjadi umbi.

Menurut Supriyatna, et al. (2016). Unsur hara $\mathrm{N}$ berpengaruh terhadap jumlah anakan dan anakan itu sendiri yang akan berkembang menjadi umbi. Dalam proses pembentukan anakan ini membutuhkan unsur hara nitrogen yang digunakan untuk pembentukan sel tanaman sehingga pemberian $\mathrm{N}$ yang optimal dapat meningkatkan laju pertumbuhan tanaman.

\section{Berat Umbi Basah}

Pada pengamatan berat basah umbi bawang merah dilakukan menggunakan alat ukur timbangan digital, dengan cara menaruh umbi di atas timbangan kemudian menentukan berat umbi bawang merah. Adapun hasil rekapitulasi berat basah tanaman bawang merah adalah sebagai berikut.

Tabel 4. Rekapitulasi Pengamatan Berat

Umbi Basah

\begin{tabular}{cc}
\hline Perlakuan & $\begin{array}{c}\text { Rata-rata Pengamatan } \\
\text { Berat Umbi Basah }\end{array}$ \\
\hline $\mathrm{P}_{0} \mathrm{D}_{1}$ & $52,31 \mathbf{a}$
\end{tabular}

$\mathrm{P}_{0} \mathrm{D}_{2}$

55,83 a

$\mathrm{P}_{0} \mathrm{D}_{3}$

54,13 a

$\mathrm{P}_{1} \mathrm{D}_{1}$

51,2 a

$\mathrm{P}_{1} \mathrm{D}_{2}$

55,93 a

$\mathrm{P}_{1} \mathrm{D}_{3}$

54 a

$\mathrm{P}_{2} \mathrm{D}_{1}$

96,2 b

$\mathrm{P}_{2} \mathrm{D}_{2}$

93,86 b

$\mathrm{P}_{2} \mathrm{D}_{3}$

97,05 c

$\mathrm{P}_{3} \mathrm{D}_{1}$

62.66 a

$\mathrm{P}_{3} \mathrm{D}_{2}$

$\mathrm{P}_{3} \mathrm{D}_{3}$

65,33 a

*Angka yang diikuti huruf yang tidak sama pada kolom yang sama menunjukkan perbedaan yang nyata.

Pada Tabel 4. Rekapitulasi berat basah umbi bawang merah dengan melakukan pengamatan setelah panen. Pada rekapitulasi berat umbi basah bawang merah notasi tertinggi adalah pada $\mathrm{P}_{2} \mathrm{D}_{3}$ sehingga terdapat adanya perbedaan yang significan pada $\mathrm{P}_{2} \mathrm{D}_{3}$. Pengaplikasian kompos limbah rumput laut Glacilaria $s p$ berbeda nyata pada tanaman bawang merah dengan Penggunaan Kompos Limbah Rumput Laut dosis $3 \mathrm{~kg}$ disertai penambahan POC Nasa/20cc terlihat pada berat umbi basah bawang merah.

Menurut Anindyawati (2010), Pupuk yang bersifat ramah lingkungan dapat memperbaiki sifat fisika, biologi dan kimia tanah serta dapat meningkatkan kehidupan mikroba tanah yang merupakan sumber hara bagi tanaman

\section{Berat Umbi Kering}


Pada pengamatan berat kering bawang merah dilakukan setelah umbi bawang merah dikeringkan. Pengamatan berat kering umbi bawang merah dilakukan menggunakan alat ukur timbangan digital, dengan cara menaruh umbi di atas timbangan kemudian menentukan berat umbi bawang merah. Adapun hasil rekapitulasi berat kering tanaman bawang merah adalah sebagai berikut.

Tabel 5. Rekapitulasi Pengamatan Berat Umbi Kering

\begin{tabular}{cc}
\hline Perlakuan & $\begin{array}{c}\text { Rata-rata Pengamatan } \\
\text { Berat Umbi Kering }\end{array}$ \\
\hline $\mathrm{P}_{0} \mathrm{D}_{1}$ & $20,36 \mathbf{a}$ \\
$\mathrm{P}_{0} \mathrm{D}_{2}$ & $20,53 \mathbf{a}$ \\
$\mathrm{P}_{0} \mathrm{D}_{3}$ & $20,26 \mathbf{a}$ \\
$\mathrm{P}_{1} \mathrm{D}_{1}$ & $23,33 \mathbf{a}$ \\
$\mathrm{P}_{1} \mathrm{D}_{2}$ & $24,13 \mathbf{a}$ \\
$\mathrm{P}_{1} \mathrm{D}_{3}$ & $25,00 \mathbf{a}$ \\
$\mathrm{P}_{2} \mathrm{D}_{1}$ & $30,93 \mathbf{a}$ \\
$\mathrm{P}_{2} \mathrm{D}_{2}$ & $31,00 \mathbf{b}$ \\
$\mathrm{P}_{2} \mathrm{D}_{3}$ & $31,4 \mathbf{c}$ \\
$\mathrm{P}_{3} \mathrm{D}_{1}$ & $30,16 \mathbf{a}$ \\
$\mathrm{P}_{3} \mathrm{D}_{2}$ & $30,33 \mathbf{a}$ \\
$\mathrm{P}_{3} \mathrm{D}_{3}$ & $29,86 \mathbf{a}$ \\
\hline
\end{tabular}

*Angka yang diikuti huruf yang tidak sama pada kolom yang sama menunjukkan perbedaan yang nyata.

Pada Tabel 5. menunjukkan rekapitulasi berat umbi kering pada pengamatan setelah panen. Hasil menunjukkan adanya perbedaan significan berat umbi kering bawang merah yang telah diamati. Pada rekapitulasi berat umbi kering bawang merah terdapat
Peningkatan notasi tertinggi berat umbi kering bawang merah yaitu pada $\mathrm{P}_{2} \mathrm{D}_{3}$.

Adanya perbedaan yang nyata terhadap penggunaan kompos limbah rumput laut Glacilaria $s p$ berbeda nyata pada tanaman bawang merah dengan Penggunaan Kompos Limbah Rumput Laut dosis $3 \mathrm{~kg}$ disertai penambahan POC Nasa/20cc terhadap produksi bawang merah berdasarkan berat kering umbi bawang merah.

Menurut Supriyatna, et al. (2016), hasil analisis rata-rata bobot kering tanaman bawang merah dengan kombinasi kompos menunjukan hasil yang berbeda nyata disebabkan karena pembentukan umbi bawang merah berasal dari pembesaran lapisan-lapisan batang semu yang kemudian berkembang menjadi umbi bawang merah. Kandungan $\mathrm{K}$ yang tinggi menyebabkan ion $\mathrm{K}+$ yang mengikat air dalam tubuh tanaman akan mempercepat proses fotosintesis. Hasil fotosintesis inilah yang merangsang pembentukan umbi menjadi lebih besar sehingga dapat meningkatkan bobot kering tanaman.

\section{SIMPULAN}

Konsentrasi terbaik Kompos Limbah Rumput Laut Gracillaria sp. yang diaplikasikan pada bawang merah adalah dengan dosis $3 \mathrm{~kg}$ disertai penambahan POC Nasa/20cc memberikan hasil yang nyata terhadap pertumbuhan dan produksi bawang merah. 


\section{DAFTAR PUSTAKA}

Annonimus. 2008. Limbah rumput laut bahan baru pupukorganik. Media Trubus.

Basmal J, et al. 2009. Mekanisasi proses pengeringan dan sistem pemisahan filtrat rumput laut. Laporan Akhir Penelitian Mekanisasi Proses. Balai Besar Riset Pengolahan Produk dan Bioteknologi Kelautan dan Perikanan.

Baswarsiati, L. Rosmahani, E. Korlina, E.P. kusumainderawati, S.Z. Sa'adah. 1996. Adaptasi Beberapa Varietas Bawang Merah Diluar Musim. Prosiding Seminar Hasil Penelitian/Pengkajian BPTP Karangploso.

Diana S. et al. (2015). Pemberian Berbagai Jenis Kompos Pada Pertumbuhan dan Hasil Tanaman Bawang Merah (Allium Ascalonicum L) di Kabupaten Enrekang. Jurusan Agroteknologi FAPERTA UNMUS. Agricola, Vol 5 (1)

Sari, I, A et al. 2014. Penguatan Sosial Ekonomi Masyarakat Lereng Merapi Melalui Adopsi Inovasi Pupuk Organik Untuk Mendukung Sistem Pertanian Peternakan Terpadu. Jurnal Unitri.

Jawa H, et al. 2014. Aplikasi Kompos Ganggang Cokelat (Sargassum polycystum) Diperkaya Pupuk N, P, K Terhadap Inseptisol dan
Jagung. Jurnal Online Agroekoteknologi . Vol.2, No.4 : 1538 1544.

Lingga, P. dan Marsono. 2001. Petunjuk Penggunaan Pupuk. Penebar Swadaya. Jakarta.

Matondang D. 2017. Stok Bawang Merah Aman Hingga Maret 2019, Tapi Petani Masih Rugi. Detik Finance.

Mukhlis, P., dan D. Anggorowati. 2011. Pengaruh Berbagai Jenis Mikroorganisme Lokal (Mol) Terhadap Pertumbuhan Dan Hasil Bawang Merah Pada Tanah Aluvial. Fakultas Pertanian Universitas Tanjungpura Pontianak.

Napitupulu, D dan L. Winarto. 2009. Pengaruh Pemberian Pupuk N Dan K Terhadap Pertumbuhan Dan Produksi Bawang Merah. Balai Pengkajian Teknologi Pertanian Sumatera Utara, J-Hort.20 (1) : 22-35 2010.

Putra P, et al. 2012. Pupuk Organik Dari Rumput Laut Pesisir Kalimantan Barat dan Aplikasinya Pada Tanaman Uji Di Tanah Aluvial. Baristand Industri Pontianak.

Rukmana, R. 1994. Bawang Merah, Budidaya Dan Pengolahan Pascapanen. Penerbit Kanisius Yogyakarta. 
Salisbury. et al. 1995. Fisiologi Tumbuhan. Penerbit ITB Bandung, Bandung. Hutchison \& Kieber, 2002).sitokinin

Sigit A, et al. (2013). Pengaruh Bioaktivator Boisca Dan Em4 Terhadap Kualitas Pupuk Organik Cair Rumput Laut Gracilaria sp. . Seminar Nasional Ke-III: Hasil-Hasil Penelitian Perikanan Dan Kelautan. Fakultas Perikanan Dan Ilmu Kelautan Universitas Diponegoro

Surianti K. 2017. Rancangan Percobaan Teori dan Aplikasi. Jakarta: PT. Gramedia.

Sedayu B, et al. (2014). Pupuk cair dari rumput laut Gracilaria sp. , sargassum sp.dan Eucheuma cottonii. Menggunakan proses pengomposan. JPB Perikanan Vol. 9 No. 1 Tahun 2014: 61-68

Widyaningsih. 2016. Teknologi budidaya bawang merah. Bali litbang.

Yuniartha L. 2019. Produksi bawang merah tahun ini diramal stabil. News data financial. 